\title{
DWI-related texture analysis for prostate cancer: differences in correlation with histological aggressiveness and data repeatability between peripheral and transition zones
}

\author{
Chie Tsuruta ${ }^{1}$, Kenji Hirata ${ }^{2}$, Kohsuke Kudo ${ }^{2,3}$, Naoya Masumori ${ }^{4}$ and Masamitsu Hatakenaka ${ }^{{ }^{*}}$ (D)
}

\begin{abstract}
Background: We investigated the correlation between texture features extracted from apparent diffusion coefficient (ADC) maps or diffusion-weighted images (DWIs), and grade group (GG) in the prostate peripheral zone (PZ) and transition zone (TZ), and assessed reliability in repeated examinations.

Methods: Patients underwent 3-T pelvic magnetic resonance imaging (MRI) before radical prostatectomy with repeated DWI using $b$-values of $0,100,1,000$, and $1,500 \mathrm{~s} / \mathrm{mm}^{2}$. Region of interest (ROI) for cancer was assigned to the first and second DWI acquisition separately. Texture features of ROls were extracted from comma-separated values (CSV) data of ADC maps generated from several sets of two $b$-value combinations and DWIs, and correlation with $\mathrm{GG}$, discrimination ability between GG of $1-2$ versus 3-5, and data repeatability were evaluated in PZ and TZ. Results: Forty-four patients with 49 prostate cancers met the eligibility criteria. In PZ, ADC 10\% and 25\% based on ADC map of two $b$-value combinations of 100 and $1,500 \mathrm{~s} / \mathrm{mm}^{2}$ and $10 \%$ based on ADC map with $b$-value of 0 and $1,500 \mathrm{~s} / \mathrm{mm}^{2}$ showed significant correlation with GG, acceptable discrimination ability, and good repeatability. In TZ, higher-order texture feature of busyness extracted from ADC map of 100 and 1,500 s/mm², and high gray-level run emphasis, short-run high gray-level emphasis, and high gray-level zone emphasis from DWI with $b$-value of $100 \mathrm{~s} /$ $\mathrm{mm}^{2}$ demonstrated significant correlation, excellent discrimination ability, but moderate repeatability.
\end{abstract}

Conclusions: Some DWI-related features showed significant correlation with GG, acceptable to excellent discrimination ability, and moderate to good data repeatability in prostate cancer, and differed between PZ and TZ.

Keywords: Diffusion magnetic resonance imaging, Image interpretation (computer-assisted), Neoplasm grading, Prostate neoplasms, Reproducibility of results

\footnotetext{
* Correspondence: mahatakenaka@sapmed.ac.jp

'Department of Diagnostic Radiology, School of Medicine, Sapporo Medical

University, South 1, West 17, Chuo-ku, Sapporo 060-8556, Japan

Full list of author information is available at the end of the article
}

\section{Springer Open}

(c) The Author(s). 2022 Open Access under exclusive licence to European Society of Radiology. This article is licensed under a Creative Commons Attribution 4.0 International License, which permits use, sharing, adaptation, distribution and reproduction in any medium or format, as long as you give appropriate credit to the original author(s) and the source, provide a link to the Creative Commons licence, and indicate if changes were made. The images or other third party material in this article are included in the article's Creative Commons licence, unless indicated otherwise in a credit line to the material. If material is not included in the article's Creative Commons licence and your intended use is not permitted by statutory regulation or exceeds the permitted use, you will need to obtain permission directly from the copyright holder. To view a copy of this licence, visit http://creativecommons.org/licenses/by/4.0/. 


\section{Key points}

- Some diffusion-weighted imaging (DWI)-related texture features significantly correlated with histological aggressiveness in prostate cancer.

- Some DWI-related texture features show clinically acceptable data repeatability in prostate cancer.

- Texture features showing correlation with histological aggressiveness and repeatability differ between zones.

- DWI with $b$-values of 100 and $1,500 \mathrm{~s} / \mathrm{mm}^{2}$ may be relevant.

\section{Background}

Texture analysis of clinical imaging has been increasingly carried out to determine its correlation with histological findings, such as lesion aggressiveness and clinical outcome [1-3]. Texture features extracted from magnetic resonance diffusion-weighted imaging (DWI), including apparent diffusion coefficient (ADC) maps, have shown promising results. However, there is no consensus regarding the method to calculate DWI-related metrics such as monoexponential fitting, intravoxel incoherent motion, and diffusion kurtosis imaging. From a clinical perspective, ADC maps calculated from two different $b$-values can be simple and easy to use, but there is no consensus regarding the use of a combination of two $b$-values. Furthermore, there are concerns regarding the reliability of texture features which are sensitive to imaging characteristics, possibly having coincidental significance due to a larger number of parameters [4-6].

Magnetic resonance imaging (MRI) is a primary imaging modality used for prostate cancer. Many studies have been reported regarding the correlation between DWI-related parameters and lesion aggressiveness, such as the Gleason score (GS) and grade group (GG), with inconsistent results. It was reported that ADC entropy showed significant difference between GS of $3+4$ and 4 +3 but not in ADC mean [7]. Alessandrino F et al. [8] reported similar results, with no significance in ADC mean. In contrast, Itou $\mathrm{Y}$ et al. [9] reported that ADC median showed a significant correlation with GS and a significant difference between GS of $3+4$ and $4+3$. Shan $\mathrm{Y}$ et al. [10] reported that ADC mean showed a significant correlation with GS and a significant difference between GS of $3+4$ and $4+3$. Though some studies evaluated data reliability focusing on intraobserver and interobserver agreement for the same images (ADC maps) $[11,12]$, few studies have been performed with respect to image data reliability itself. Furthermore, though the above studies dealt with cancers in the peripheral zone (PZ) and transition zone (TZ) together, Hambrock $\mathrm{T}$ et al. [13] reported that ADC median showed a significant correlation with Gleason grade in PZ cancer. Jyoti $\mathrm{R}$ et al. [14] also reported that ADC minimum was significantly correlated with GS in PZ cancer, but not in TZ cancer. These results raise the possibility that DWIrelated features may demonstrate a different relationship with tumor aggressiveness between the $\mathrm{PZ}$ and $\mathrm{TZ}$. In a recent systematic review, Surov A et al. [15] reported that in PZ cancer, ADC moderately correlates with GS, but it weakly correlated with in $\mathrm{TZ}$ cancer.

This study aimed to analyze the correlation between texture features extracted from ADC maps generated from several sets of two $b$-value combinations or DWIs with several $b$-values, and GG in the PZ and TZ, separately, and to evaluate the reliability of texture features in repeated examinations.

\section{Methods}

Population, inclusion, and exclusion criteria

This study was compliant with Helsinki Declaration. The following inclusion and exclusion criteria were considered: Inclusion criteria: patients who underwent 3-T multiparametric MRI (mpMRI) at our institute, including two sets of repeated DWI acquisitions for evaluating prostate lesions with informed consent from July 2016 to May 2020. Exclusion criteria: treatment except radical prostatectomy; lesions with a longitudinal diameter $<10$ $\mathrm{mm}$; lesions not detected on DWI; lesions with a voxel number within the region of interest $(\mathrm{ROI})<50$; lesions containing voxel with $\mathrm{ADC}$ value $<0$; poor image quality. Figure 1 shows the flowchart of patient inclusion and exclusion.

\section{MRI}

MRI was performed using a 3-T system (Ingenia, Philips Healthcar, Eindhoven, The Netherlands) with a pelvic phased-array coil. No endorectal coil was used. Either 20-mg hyoscine-N-butyl-bromide or 1-mg glucagon was injected intramuscularly before examination to minimize bowel peristalsis.

A routine mpMRI protocol was applied to all patients, including sagittal, coronal, and axial T2-weighted imaging; axial DWIs; and axial dynamic contrast-enhanced imaging before and after gadolinium chelate injection of $0.1 \mathrm{mmol} / \mathrm{kg}$ gadoterate meglumine, Magnescope, Dotarem (Guerbet, Villepinte, France). For DWI, two sequential free-breathing DWI single-shot spin-echo echoplanar images were acquired. The patient remained in the same position between the two DWI acquisitions. Four $b$-values $\left(0,100,1,000\right.$, and $\left.1,500 \mathrm{~s} / \mathrm{mm}^{2}\right)$ with three orthogonal diffusion probing gradients were generated. ADC maps were generated using DWIs with $b$ values of 100 and $1,000 \mathrm{~s} / \mathrm{mm}^{2}, \operatorname{ADC}$ map $(100,1,000)$ in line with the Prostate Imaging-Reporting and Data System (PI-RADS) version 2.1 (https://www.acr.org/-/ media/ACR/Files/RADS/PI-RADS/PIRADS-V2-1.pdf) for the first and second DWIs, respectively. The DWI 


\section{Patients who underwent $3 \mathrm{~T} \mathrm{mpMRI}$ including two sets of DWIs for suspected prostate cancer $(n=296)$}

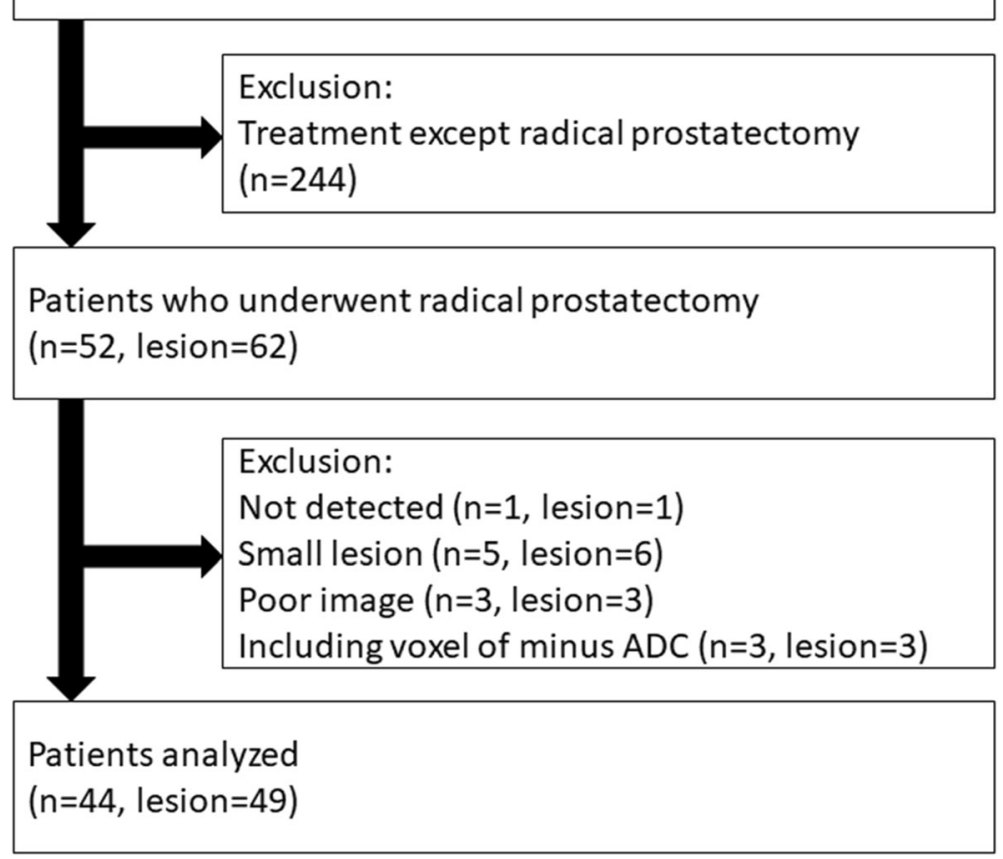

Fig. 1 Flowchart of study showing inclusion and exclusion criteria, and patient and lesion numbers

sequence parameters are summarized in Supplemental Table S1.

\section{Image analysis}

Image analysis including ROI assignment was performed by a consensus decision of two observers (C.T. and M.H. with 4 and over 30 years of experience in diagnostic radiology, respectively) using a Synapse Vincent 3D Image Analysis System (Fujifilm Corporation, Tokyo, Japan). For PZ cancer, the polygonal two-dimensional ROI was manually determined on the lesion in the center slice showing hyperintensity on the first DWI with a $b$-value of $1,500 \mathrm{~s} / \mathrm{mm}^{2}$ (DWI 1,500) and hypointensity on the first ADC map $(100,1,000)$, referring to T2weighted imaging, dynamic contrast-enhanced imaging, and whole-mount, step-sectioned histological evaluation of prostatectomy specimen. Then, the ROI was placed on the first DWI datasets of DWI 0, DWI 100, and DWI 1,000 through IVIM application of a Synapse Vincent 3D Image Analysis System. For non-peripheral transition zone (TZ) cancers, the polygonal two-dimensional ROI was manually determined on the lesion in the center slice showing hypointensity on T2-weighted images and hyperintensity on the first DWI 1,500 , referring to the first ADC map (100, 1,000), dynamic contrast-enhanced imaging, and whole-mount, step-sectioned histological evaluation of prostatectomy specimen. After this, the ROI was placed on the first DWI datasets of DWI 0 , DWI 100, and DWI 1,000 through intravoxel incoherent motion (IVIM) application of the Synapse Vincent 3D Image Analysis System. The same procedures were repeated for the second DWI datasets. Voxel data distributions within the ROI were rendered in comma-separated values (CSV) format (Supplemental Figs. S1 and S2) using a Synapse Vincent 3D Image Analysis System. Then, the ADC of each voxel was calculated by fitting signal intensity decay between four patterns of $b$-value combinations using a monoexponential curve fit: 0 and $1,000 \mathrm{~s} / \mathrm{mm}^{2}, \operatorname{ADC}(0,1,000) ; 0$ and $1,500 \mathrm{~s} / \mathrm{mm}^{2}, \mathrm{ADC}$ $(0,1,500) ; 100$ and $1,000 \mathrm{~s} / \mathrm{mm}^{2}, \operatorname{ADC}(100,1,000)$; and 100 and $1,500 \mathrm{~s} / \mathrm{mm}^{2}$, ADC (100, 1,500). Representative cases are shown in Figs. 2 and 3.

We assigned a two-dimensional ROI in the center slice of the lesion because more than half lesions were not large enough to place a three-dimensional ROI. Only 21 lesions, $43 \%$ of total lesions, showed longitudinal diameter $>12 \mathrm{~mm}$ on images and could be determined on equal to or more than four slices (DWI slice thickness of $3 \mathrm{~mm} /$ gap of $0 \mathrm{~mm}$, Supplemental Table 1) that would have satisfied assigning ROIs on two or more slices avoiding peripheral images, possibly being affected by partial volume effect. Texture analysis calculates the 

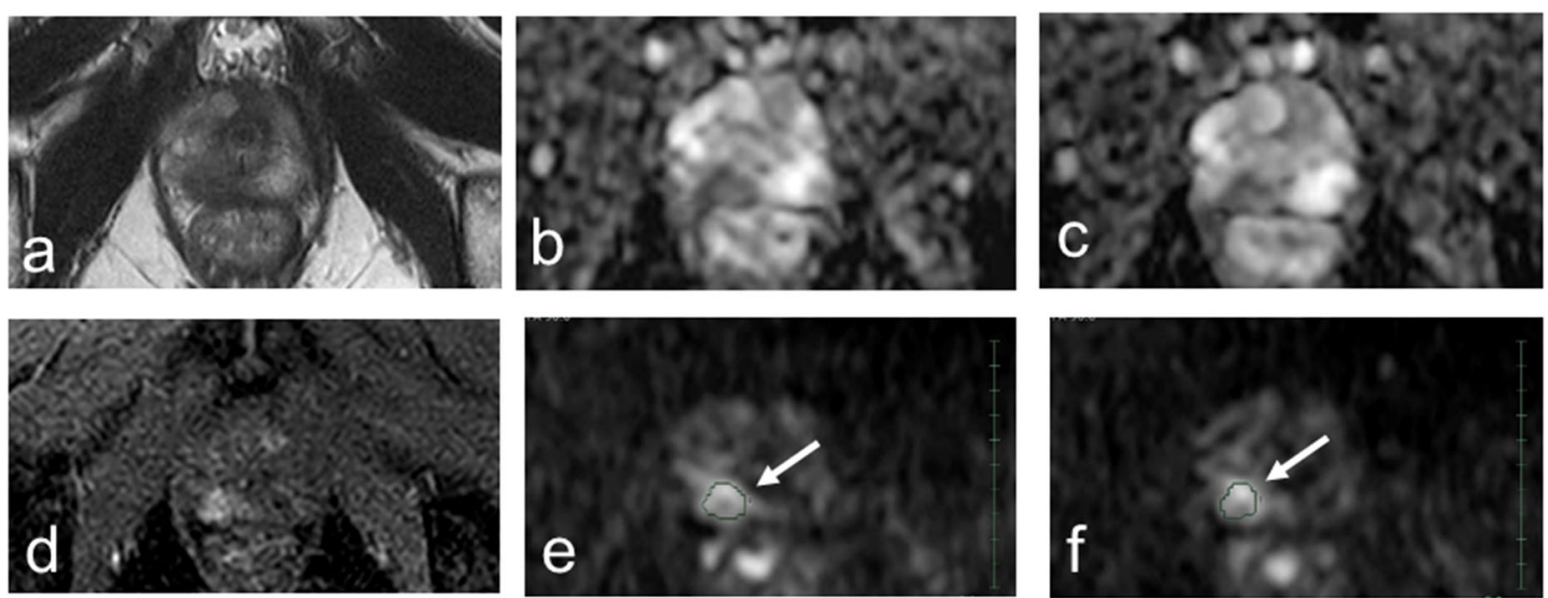

Fig. 2 Multiparametric magnetic resonance imaging of the case (70 years, right peripheral zone cancer, GG of 3, PI-RADS of 4, T2aNOM0). a Axial T2-weighted image (repetition time of 4,000 ms and echo time of $80 \mathrm{~ms}$ ). b First axial apparent diffusion coefficient (ADC) map (100, 1,000). c Second axial ADC map $(100,1,000)$. d Dynamic contrast-enhanced T1-weighted image. e First DWI 1,500. f Second DWI 1,500. Arrows indicate polygonal areas of the region of interests on $\mathbf{e}$ and $\mathbf{f}$

relationship between adjacent voxels, and thus, we assumed that appropriate texture analysis required at least four voxels along each direction.

All voxels within the ROI were extracted from the CSV data of $\operatorname{ADC}(0,1,000),(0,1,500),(100,1,000)$, and $(100,1,500)$, and DWI $0,100,1,000$, and 1,500 . First-order statistical variables (minimum, 10\%, 25\%, median, 75\%, 90\%, maximum, mean, sum, standard deviation, skewness, kurtosis, energy, and entropy) were calculated. After discretization of voxel values (bin number 32), higher-order texture analysis was performed in a two-dimensional manner to generate a gray-level co-occurrence matrix (GLCM), gray-level run-length matrix (GLRLM), gray-level zone-size matrix (GLZSM), and neighborhood gray-level difference matrix (NGLDM). Homogeneity, energy, correlation, contrast, entropy, and dissimilarity were calculated from the GLCM. Short-run emphasis (SRE), long-run emphasis (LRE), low gray-level run emphasis (LGRE), high gray-level run emphasis (HGRE), short-run low gray-level emphasis (SRLGE), short-run high gray-level emphasis (SRHGE), long-run low gray-level emphasis (LRLGE), long-run high graylevel emphasis (LRHGE), gray-level non-uniformity for run (GLNUr), run-length non-uniformity (RLNU), and run percentage (RP) were calculated from GLRL M. Short-zone emphasis (SZE), long-zone emphasis (LZE), low gray-level zone emphasis (LGZE), high
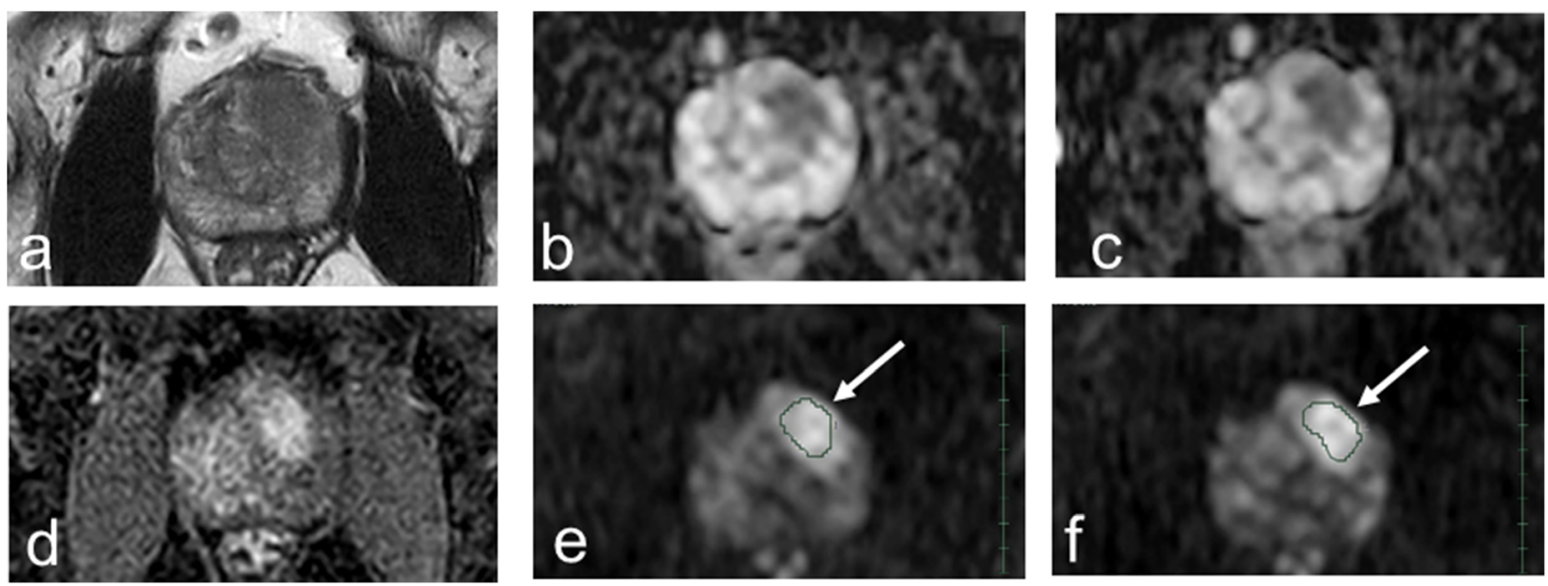

Fig. 3 Multiparametric magnetic resonance imaging of the case (61 years, transition zone cancer, GG of 2, PI-RADS of 5, T2cNOM0). a Axial T2weighted image (repetition time of 4,000 $\mathrm{ms}$ and echo time of $80 \mathrm{~ms}$ ). b First axial apparent diffusion coefficient (ADC) map (100, 1,000). c Second axial ADC map $(100,1,000)$. d Dynamic contrast-enhanced T1-weighted image. e First DWI 1,500. f Second DWI 1,500. Arrows indicate polygonal areas of the region of interests on $\mathbf{e}$ and $\mathbf{f}$ 
gray-level zone emphasis (HGZE), short-zone low gray-level emphasis (SZLGE), short-zone high graylevel emphasis (SZHGE), long-zone low gray-level emphasis (LZLGE), long-zone high gray-level emphasis (LZHGE), gray-level non-uniformity for zone (GLNUz), zone length non-uniformity (ZLNU), and zone percentage (ZP) were calculated from GLZSM. Coarseness, contrast, and busyness were calculated from NGLDM. Texture features were computed using the PTexture package (www.github.com/metavol/ ptexture) written in Python language. The detailed methods are described elsewhere [16].

\section{Statistical analysis}

Statistical analyses were carried out separately for PZ and TZ cancers. First, the correlation between texture features and GG was evaluated using Spearman's rank correlation test. For the features showing significance at both the first and second examinations, receiver operating characteristic (ROC) curves for differentiating between GG of 1 and 2 versus GG of 3, 4, and 5 were drawn, and the area under the curve (AUC) was calculated because there was a difference in prognosis between GG of 1 and 2, versus GG of 3, 4, and 5 [17]. To check test-retest data repeatability, intraclass correlation coefficient (ICC) and Bland-Altman plot (\%) (\% difference was used to normalize differences in original data magnitude) were used. Statistical analyses were performed using GraphPad Prism ver. 7.05 (GraphPad Software, San Diego, USA) and SPSS statistics ver. 25 (International Business Machines Corporation, Armonk, USA); $p$-values $<0.05$ were considered statistically significant.

We considered the following values for classifying the strength of correlation: moderate $(|\rho|: 0.4-0.7)$, strong $(|\rho|: 0.7-0.9)$, and very strong $(|\rho|: 0.9-1)$ [18], discrimination ability: acceptable (AUC: $0.7-0.8$ ), excellent (AUC: $0.8-0.9$ ), and outstanding (AUC > 0.9) [18], and data repeatability: moderate (ICC: $0.5-0.75)$, good: (ICC: $0.75-$ 0.9 ), and excellent (ICC: 0.9-1) [19].

\section{Results}

From July 2016 to May 2020, a total of 296 patients with suspected prostate cancer underwent mpMRI including two sets of repeated DWI acquisitions for evaluating prostate lesions with informed consent. Among them, 52 patients underwent mpMRI before prostatectomy and were histologically diagnosed as prostate cancer by the institutional pathologists. There were 62 cancers with a longitudinal diameter $\geq 10 \mathrm{~mm}$. Furthermore, one lesion undetected on DWI, six lesions with a voxel number within the $\mathrm{ROI}<50$, three lesions with poor image quality either in the first or second DWI, and three lesions containing voxel with $\mathrm{ADC}$ value $<0$ were excluded.
Finally, 44 patients with 49 cancers were analyzed. The characteristics of patients and lesions are summarized in Table 1. Of them, 11 patients underwent prostate biopsy within 6 weeks (17-36 days) before mpMRI, but no clear adverse effects were included for analysis. The duration between MRI and radical prostatectomy was from 8 to 191 days (median 69 days).

As a representative of ADC histograms, ADC $10 \%$ calculated from $\operatorname{ADC}(0,1,000),(0,1,500),(100,1,000)$, and $(100,1,500)$ are summarized in Table 2 and classified according to the PZ and TZ as well as GG.

In PZ cancer, the following metrics showed significant correlation with GG at both examinations: ADC 10\% and $25 \%$ based on $\operatorname{ADC}(0,1,000)$; ADC $5 \%, 10 \%$, and $25 \%$ based on $\operatorname{ADC}(0,1,500)$; ADC $10 \%, 25 \%$, and $50 \%$ based on ADC $(100,1,000)$; and ADC 5\%, 10\%, and $25 \%$ based on $\mathrm{ADC}(100,1,500)$. Other metrics including higher-order texture features did not show significance. The results, including Spearman's $\rho$ and its 95\% confidence interval, the AUC of ROC for differentiation between GG of 1 and 2 versus GG of 3, 4, and 5, ICC and its $95 \%$ confidence interval, and Bland-Altman analysis (\%) (bias, standard deviation of bias, 95\% limit of agreement), are summarized in Table 3 . Among them, as ADC $10 \%$-based on ADC $(0,1,500)$ and ADC $(100$, $1,500)$ as well as ADC $25 \%$ based on $\operatorname{ADC}(100,1,500)$ showed moderate correlation coefficient with GG $(|\rho|>$ $0.4, p<0.05$ ), acceptable discrimination ability (AUC >

Table 1 Summary of patient and lesion characteristics

\begin{tabular}{lr}
\hline Parameter & Value \\
\hline No. of patients & 44 \\
Median age (year), (range) & 48 (49-79) \\
No. of cancers & 1 \\
PI-RADS 2.1 score & 38 \\
3 & 10 \\
4 & \\
5 & 1 \\
Grade group & 27 \\
1 & 16 \\
2 & 3 \\
3 & 2 \\
4 & \\
5 &
\end{tabular}

Location of cancer

Peripheral zone

Not peripheral zone (Transition zone)

19

Number of voxels included in the ROI

First, median, (range)

$104(58-231)$

Second, median, (range)

$101(51-271)$

PI-RADS Prostate Imaging-Reporting and Data System, $R O I$ Region of interest 
Table 2 Summary of the breakdown of ADC 10\% according to grade group and the $b$-value combination in peripheral and transition zones

\begin{tabular}{|c|c|c|c|c|c|}
\hline \multirow{2}{*}{\multicolumn{2}{|c|}{$\begin{array}{l}\text { Zone/grade } \\
\text { group }\end{array}$}} & \multicolumn{4}{|c|}{ Combination of two $b$-values $\times \mathrm{s} / \mathrm{mm}^{2}$} \\
\hline & & $(0,1,000)$ & $(0,1,500)$ & $(100,1,000)$ & $(100,1,500)$ \\
\hline Peripheral zon & & \multicolumn{4}{|c|}{ First/second of ADC $10 \% \times 10^{-3} \mathrm{~mm}^{2} / \mathrm{s}$} \\
\hline \multirow[t]{5}{*}{ Grade group } & 1 & $0.763 / 0.869$ & $0.663 / 0.743$ & $0.760 / 0.857$ & $0.648 / 0.694$ \\
\hline & 2 & $0.767 / 0.782$ & $0.660 / 0.678$ & $0.651 / 0.694$ & $0.584 / 0.612$ \\
\hline & 3 & $0.595 / 0.633$ & $0.525 / 0.572$ & $0.505 / 0.541$ & $0.452 / 0.490$ \\
\hline & 4 & $0.609 / 0.654$ & $0.537 / 0.599$ & $0.557 / 0.558$ & $0.482 / 0.532$ \\
\hline & 5 & $0.529 / 0.517$ & $0.431 / 0.451$ & $0.454 / 0.438$ & $0.386 / 0.397$ \\
\hline Transition zon & & \multicolumn{4}{|c|}{ First/second of ADC $10 \% \times 10^{-3} \mathrm{~mm}^{2} / \mathrm{s}$} \\
\hline \multirow[t]{5}{*}{ Grade group } & 1 & - & - & - & - \\
\hline & 2 & $0.708 / 0.676$ & $0.626 / 0.598$ & $0.636 / 0.584$ & $0.566 / 0.536$ \\
\hline & 3 & $0.745 / 0.744$ & $0.659 / 0.658$ & $0.700 / 0.637$ & $0.610 / 0.555$ \\
\hline & 4 & $0.748 / 0.733$ & $0.682 / 0.653$ & $0.645 / 0.728$ & $0.656 / 0.573$ \\
\hline & 5 & $0.741 / 0.773$ & $0.636 / 0.634$ & $0.638 / 0.592$ & $0.456 / 0.563$ \\
\hline
\end{tabular}

0.7) at both examinations, and good data repeatability (ICC > 0.8). The correlation between GG and ADC 10\% mean of the first and second examinations based on ADC $(100,1,500)$, and their XY plot are shown in Fig. 4. To demonstrate the difference between the $\mathrm{PZ}$ and $\mathrm{TZ}$, the correlation between GG and ADC $10 \%$ mean of the first and second examinations based on ADC (100,
1,500), and their XY plot in TZ cancer are also shown in Supplemental Fig. S3.

For TZ cancer, SRHGE and busyness based on ADC (100, 1,500), and skewness, HGRE, SRHGE, LRHGE, HGZE, SZHGE, and busyness based on DWI 100, and skewness, HGRE, SRHGE, and HGZE based on DWI 0 showed significant correlations with GG. As opposed to $\mathrm{PZ}$, the first-order statistical metrics did not show significance. The results, including Spearman's $\rho$ and its 95\% confidence interval, the ROC-AUC of for differentiating GG of 1 and 2 from GG of 3, 4, and 5, ICC and its 95\% confidence interval, and Bland-Altman analysis (\%) (bias, standard deviation of bias, 95\% limit of agreement) are summarized in Table 4. Among them, busyness based on ADC $(100,1,500)$, and HGRE, SRHGE, and HGZE based on DWI 100 demonstrated moderate correlation coefficients with GG $(|\rho|>0.5, p<0.05)$, excellent discrimination ability (AUC $>0.8$ ) at both examinations, and moderate data repeatability (ICC > 0.5; skewness based on DWI 100 or 0 was excluded due to large standard deviation [> 300\%] in Bland-Altman analysis [\%]). The correlation between GG, and busyness mean of the first and second examinations based on $\operatorname{ADC}(100,1,500)$ and HGRE mean of the first and second examinations based on DWI 100, and their XY plot are shown in Figs. 5 and 6, respectively.

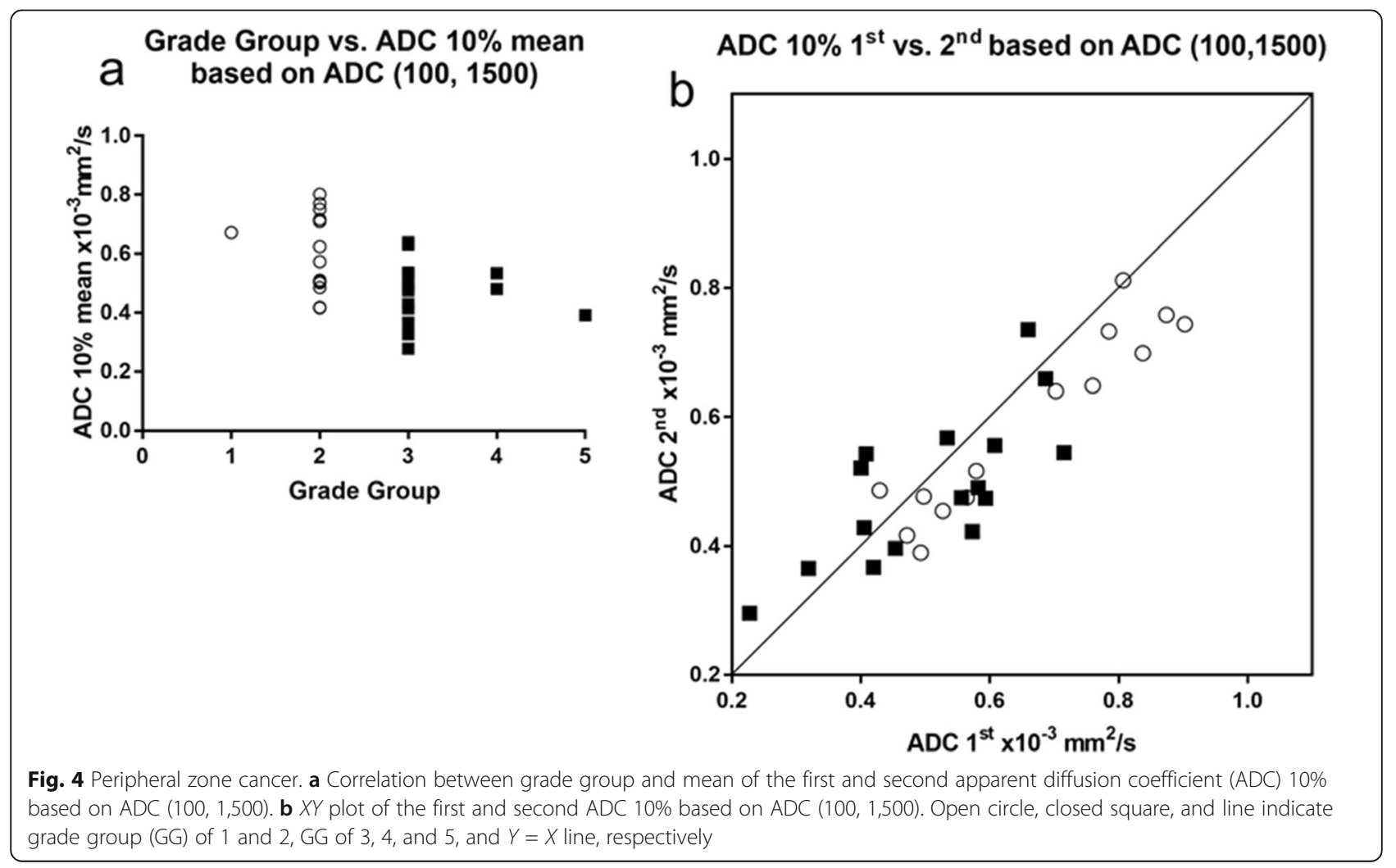




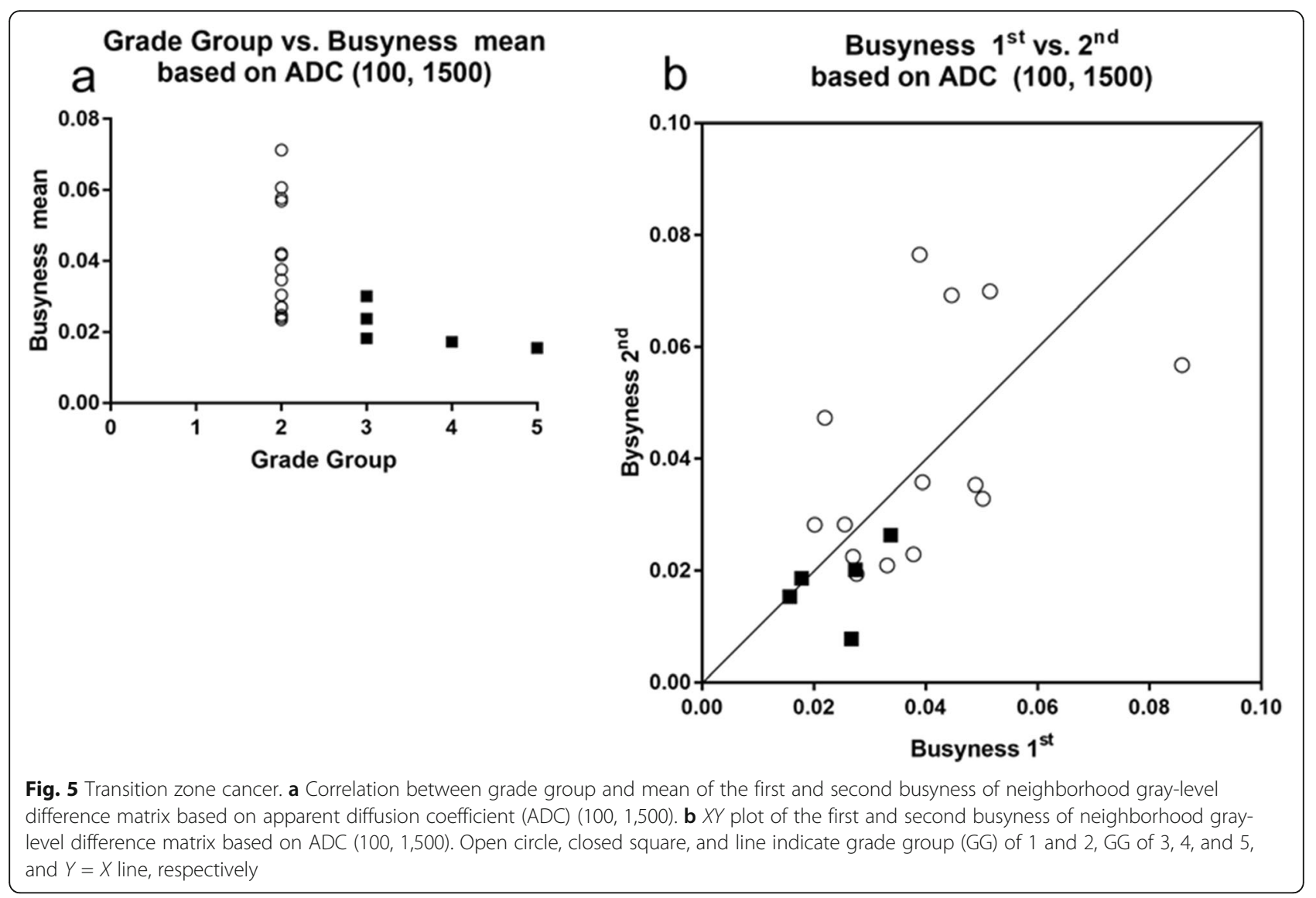

\section{Discussion}

To our knowledge, this is the first study showing a difference in DWI-related texture features that demonstrate not only significant correlations with GG and discrimination ability between GG of 1 and 2, versus GG of 3,4 , and 5 , but also practical data repeatability between the $\mathrm{PZ}$ and $\mathrm{TZ}$ in prostate cancer.

In $\mathrm{PZ}$ cancer, $\mathrm{ADC} 10 \%$ based on $\operatorname{ADC}(0,1,500)$ and $(100,1,500)$ as well as ADC $25 \%$ based on ADC $(100,1,500)$ satisfied moderate correlation and had acceptable discrimination and good repeatability. These results were in accordance with a systematic review reporting that ADC correlated moderately with GS (correlation coefficient of $-0.48,95 \%$ confidence interval of -0.54 to -0.42 ) [15]. However, Hectors SJ et al. [20] reported that SRE and LRE using bin 16 extracted from ADC map showed significance with GS. Several differences, such as analyzing the PZ and $\mathrm{TZ}$ together, calculating ADC with four $b$-values (0, $1,000,1,600$, and $\left.2,000 \mathrm{~s} / \mathrm{mm}^{2}\right)$, and measuring texture feature using different methods, could explain the differences. Baek $\mathrm{T}$ et al. [21] reported that the entropy of GLCM from ADC map generated from $b$ values of 0 and $1,000 \mathrm{~s} / \mathrm{mm}^{2}$ showed significance with GS. The differences in analyzing the $\mathrm{PZ}$ and $\mathrm{TZ}$ together and the distribution of lesion aggressiveness (16 out of total 65 lesions were GS of 6), including 19 biopsy-proven lesions, might explain the discrepancy. When analyzed by combining PZ and TZ cancers, the entropy of GLCM based on $\operatorname{ADC}(0,1,000)$ did not show significance either in bin of 8,16 , or 32 setting (Supplemental Table S2).

In TZ cancer, busyness based on ADC (100, 1,500), and HGRE, SRHGE, and HGZE based on DWI 100 demonstrated moderate correlation coefficients, excellent discrimination, and moderate data repeatability. To evaluate the effect of bin number, texture features using bin 8 and 16 were also analyzed. Similar results were obtained (Supplemental Tables S3 and S4). In general, texture features for $\mathrm{TZ}$ cancer tend to show higher correlation and discrimination but lower data repeatability than those for PZ cancer.

Another important finding is that ADC histogram metrics such as $10 \%$, which showed significance in PZ cancer, showed no significance in TZ cancer (Supplemental Fig. S3). This result was not inconsistent with the results of a systematic review, which reported that ADC correlated weakly (correlation coefficient of -0.22 , $95 \%$ confidence interval of -0.47 to +0.03 ) with GS in TZ cancer [15]. Furthermore, ADC 10\% did not show 


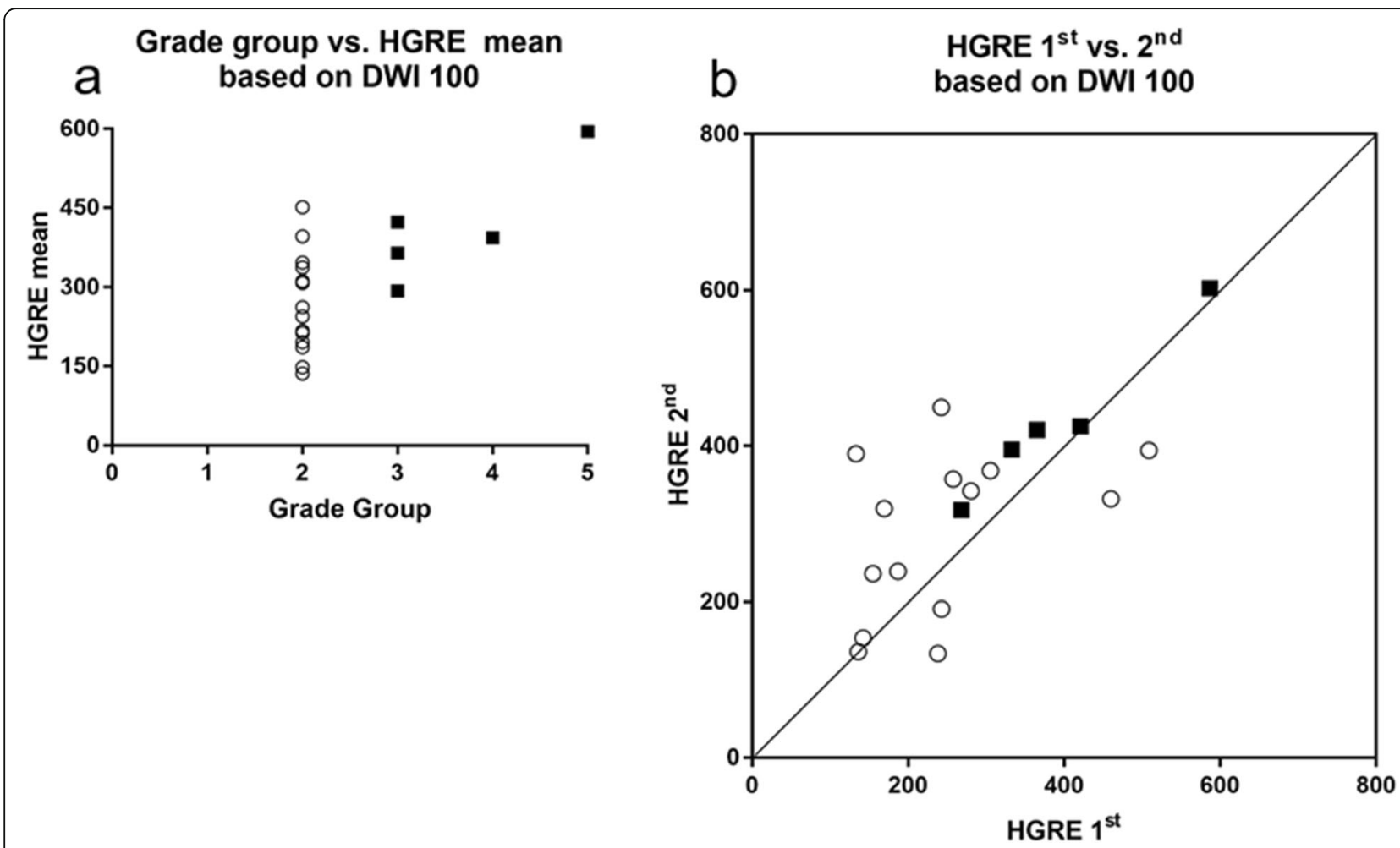

Fig. 6 Transition zone cancer. a Correlation between grade group and mean of the first and second high gray-level run emphasis of gray-level run-length matrix based on diffusion-weighted (DWI) 100. b XY plot of the first and second high gray-level run emphasis of gray-level run-length matrix based on DWI 100. Open circle, closed square, and line indicate grade group (GG) of 1 and 2, GG of 3, 4, and 5, and $Y=X$

line, respectively

significance and some features from DWI 100 and 0 demonstrating significance in TZ cancer may indirectly support that PI-RADS 2.1 puts emphasis on the findings of T2-weighted imaging for TZ cancer, because DWI with low $b$-value looks similar to fat-saturated T2weighted imaging. However, it is unclear why DWIrelated features showing significance with GG differ between $\mathrm{PZ}$ and TZ. One possible explanation might be that while the volume of the lumen and stroma is positively correlated with $\mathrm{ADC}$, that of the epithelium is negatively correlated [22], and the degree of each composition differs between the PZ and TZ [23]. This may explain the results. However, the detailed mechanism underlying this is unknown.

Regarding which two $b$-value combination is appropriate for calculating ADC, ADC generated from DWI 100 and 1,500 would be relevant in terms of a correlation with GG (Tables 3 and 4). We cannot interpret these results with reasonable model and/or relevant hypothesis at this time but image quality improvement of DWI 1,500 due to performance advance of MRI-system would contribute to these results. In a study comparing diagnostic ability of prostate cancer based on DWI-related features, ADC value calculated from DWIs with $b$-values of 50 and $1,500 \mathrm{~s} / \mathrm{mm}^{2}$ using a mono-exponential method reported to show the highest AUC among the IVIM, kurtosis, and IVIM-kurtosis methods [24], which is consistent with ours.

Another focus of the present study is data repeatability. DWI-related features with significance for PZ cancer demonstrated good repeatability, but those for TZ cancer remained moderate. However, moderate repeatability may be acceptable in clinical practice. In a previous study, the $\mathrm{K}$ value for the reproducibility of the PI-RADS 2 score in TZ was 0.525 [25]. In another study, ICCs of lesion size in the TZ were 0.80 and 0.58 for intra-reader and inter-reader analyses, respectively [26].

Texture features themselves have high potential with respect to correlation with lesion aggressiveness and clinical outcome. However, those have a tendency prone to be affected by a mild difference of the imaging data including artifacts. Therefore, reliability studies not only for observers but also for imaging data themselves should be verified sufficiently before being applied to clinical practice.

This study has some limitations. First, we analyzed patients who underwent radical prostatectomy because of the clear correlation between histology and mpMRI, but this concept would have reduced the number of the 
Table 3 Summary of the correlation between features and grade group as well as the repeatability in peripheral zone cancer

\begin{tabular}{|c|c|c|c|c|c|c|c|c|c|c|}
\hline \multirow{2}{*}{$\begin{array}{l}\text { Base } \\
\text { image/ } \\
\text { features }\end{array}$} & \multirow{2}{*}{$\begin{array}{l}\text { First/ } \\
\text { second }\end{array}$} & \multicolumn{3}{|l|}{ Grade group } & \multirow{2}{*}{$\begin{array}{l}\text { Grade group } 1,2 \text { vs. } 3, \\
4,5 \\
\text { AUC of ROC }\end{array}$} & \multirow[t]{2}{*}{ ICC } & \multirow[t]{2}{*}{$95 \% \mathrm{Cl}$} & \multicolumn{3}{|c|}{ Bland-Altman plot (\%) } \\
\hline & & $\begin{array}{l}\text { Spearman's } \\
\rho\end{array}$ & $95 \% \mathrm{Cl}$ & $p$ & & & & Bias & $\begin{array}{l}\text { SD of } \\
\text { bias }\end{array}$ & $95 \%$ LOA \\
\hline \multicolumn{11}{|c|}{$\operatorname{ADC}(0,1,000)$} \\
\hline \multirow[t]{2}{*}{$\begin{array}{l}\text { ADC } \\
10 \%\end{array}$} & First & -0.4027 & $\begin{array}{l}-0.6725 \text { to } \\
-0.03854\end{array}$ & 0.0273 & 0.732 & 0.773 & $\begin{array}{l}0.580 \text { to } \\
0.885\end{array}$ & -0.2016 & 21.15 & $\begin{array}{l}-41.65 \text { to } \\
41.25\end{array}$ \\
\hline & Second & -0.4241 & $\begin{array}{l}-0.6864 \text { to } \\
-0.06427\end{array}$ & 0.0195 & 0.737 & & & & & \\
\hline \multirow[t]{2}{*}{$\begin{array}{l}\text { ADC } \\
25 \%\end{array}$} & First & -0.3638 & $\begin{array}{l}-0.6467 \text { to } \\
0.007035\end{array}$ & 0.0481 & 0.705 & 0.825 & $\begin{array}{l}0.667 \text { to } \\
0.912\end{array}$ & 0.06553 & 15.54 & $\begin{array}{l}-30.40 \text { to } \\
30.53\end{array}$ \\
\hline & Second & -0.411 & $\begin{array}{l}-0.6779 \text { to } \\
-0.04843\end{array}$ & 0.0241 & 0.728 & & & & & \\
\hline \multicolumn{11}{|c|}{$\operatorname{ADC}(0,1,500)$} \\
\hline \multirow[t]{2}{*}{$\operatorname{ADC} 5 \%$} & First & -0.3738 & $\begin{array}{l}-0.6534 \text { to } \\
-0.004499\end{array}$ & 0.0419 & 0.705 & 0.817 & $\begin{array}{l}0.654 \text { to } \\
0.908\end{array}$ & -8.692 & 19.58 & $\begin{array}{l}-47.08 \text { to } \\
29.69\end{array}$ \\
\hline & Second & -0.4389 & $\begin{array}{l}-0.6959 \text { to } \\
-0.08239\end{array}$ & 0.0152 & 0.759 & & & & & \\
\hline \multirow[t]{2}{*}{$\begin{array}{l}\text { ADC } \\
10 \%\end{array}$} & First & -0.418 & $\begin{array}{l}-0.6824 \text { to } \\
-0.05691\end{array}$ & 0.0215 & 0.737 & 0.829 & $\begin{array}{l}0.674 \text { to } \\
0.915\end{array}$ & -7.875 & 15.9 & $\begin{array}{l}-39.04 \text { to } \\
23.29\end{array}$ \\
\hline & Second & -0.463 & -0.7111 to -0.1123 & 0.01 & 0.763 & & & & & \\
\hline \multirow{2}{*}{$\begin{array}{l}A D C \\
25 \%\end{array}$} & First & -0.4035 & -0.673 to -0.03941 & 0.027 & 0.714 & 0.865 & 0.738 to & -5.203 & 11.99 & -28.71 to \\
\hline & Second & -0.3736 & $\begin{array}{l}-0.6532 \text { to } \\
-0.004216\end{array}$ & 0.042 & 0.71 & & 0.933 & & & 18.31 \\
\hline \multicolumn{11}{|c|}{$\operatorname{ADC}(100,1,000)$} \\
\hline \multirow[t]{2}{*}{$\begin{array}{l}\text { ADC } \\
10 \%\end{array}$} & First & -0.4083 & $\begin{array}{l}-0.6761 \text { to } \\
-0.04522\end{array}$ & 0.0251 & 0.732 & 0.75 & $\begin{array}{l}0.542 \text { to } \\
0.872\end{array}$ & -6.843 & 21.59 & $\begin{array}{l}-49.16 \text { to } \\
35.47\end{array}$ \\
\hline & Second & -0.5043 & -0.7368 to -0.1652 & 0.0045 & 0.786 & & & & & \\
\hline \multirow[t]{2}{*}{$\begin{array}{l}\text { ADC } \\
25 \%\end{array}$} & First & -0.4103 & $\begin{array}{l}-0.6774 \text { to } \\
-0.04755\end{array}$ & 0.0243 & 0.723 & 0.786 & $\begin{array}{l}0.601 \text { to } \\
0.892\end{array}$ & -4.467 & 15.91 & $\begin{array}{l}-35.66 \text { to } \\
26.73\end{array}$ \\
\hline & Second & -0.4555 & -0.7064 to -0.1029 & 0.0114 & 0.754 & & & & & \\
\hline \multirow[t]{2}{*}{$\begin{array}{l}A D C \\
50 \%\end{array}$} & First & -0.3794 & $\begin{array}{l}-0.6571 \text { to } \\
-0.01101\end{array}$ & 0.0387 & 0.692 & 0.82 & $\begin{array}{l}0.658 \text { to } \\
0.910\end{array}$ & -3.982 & 11.12 & $\begin{array}{l}-25.77 \text { to } \\
17.81\end{array}$ \\
\hline & Second & -0.4013 & -0.6715 to -0.0368 & 0.028 & 0.714 & & & & & \\
\hline \multicolumn{11}{|c|}{$\operatorname{ADC}(100,1,500)$} \\
\hline \multirow[t]{2}{*}{ ADC 5\% } & First & -0.3903 & $\begin{array}{l}-0.6643 \text { to } \\
-0.02385\end{array}$ & 0.033 & 0.719 & 0.816 & $\begin{array}{l}0.651 \text { to } \\
0.907\end{array}$ & -4.456 & 18.31 & $\begin{array}{l}-40.35 \text { to } \\
31.44\end{array}$ \\
\hline & Second & -0.4142 & $\begin{array}{l}-0.6799 \text { to } \\
-0.05222\end{array}$ & 0.0229 & 0.746 & & & & & \\
\hline \multirow[t]{2}{*}{$\begin{array}{l}\text { ADC } \\
10 \%\end{array}$} & First & -0.4275 & $\begin{array}{l}-0.6886 \text { to } \\
-0.06841\end{array}$ & 0.0184 & 0.741 & 0.839 & $\begin{array}{l}0.692 \text { to } \\
0.920\end{array}$ & -6.85 & 12.82 & $\begin{array}{l}-31.97 \text { to } \\
18.27\end{array}$ \\
\hline & Second & -0.4591 & -0.7087 to -0.1074 & 0.0107 & 0.763 & & & & & \\
\hline \multirow[t]{2}{*}{$\begin{array}{l}\text { ADC } \\
25 \%\end{array}$} & First & -0.4528 & $\begin{array}{l}-0.7047 \text { to } \\
-0.09954\end{array}$ & 0.012 & 0.746 & 0.843 & $\begin{array}{l}0.699 \text { to } \\
0.922\end{array}$ & -5.629 & 10.96 & $\begin{array}{l}-27.10 \text { to } \\
15.85\end{array}$ \\
\hline & Second & -0.4039 & $\begin{array}{l}-0.6733 \text { to } \\
-0.03999\end{array}$ & 0.0268 & 0.732 & & & & & \\
\hline
\end{tabular}

95\% Cl 95\% confidence interval, 95\% LOA 95\% Limit of agreement, AUC Area under the curve, ICC Intraclass correlation coefficient, ROC Receiver operating characteristic, SD Standard deviation

cases and lesions included in the study. Second, texture features of T2-weighted imaging were not evaluated because matrix size was different from DWI and the voxel number in the ROI differed greatly. Third, texture features were extracted from two-dimensional ROI because the lesion size was not large enough to extract features from three-dimensional ROI. Fourth, ROI assignment was performed by consensus between two 
Table 4 Summary of the correlation between features and grade group as well as the repeatability in transition zone cancer

\begin{tabular}{|c|c|c|c|c|c|c|c|c|c|c|}
\hline \multirow{2}{*}{$\begin{array}{l}\text { Base } \\
\text { image/ } \\
\text { features }\end{array}$} & \multirow{2}{*}{$\begin{array}{l}\text { First/ } \\
\text { second }\end{array}$} & \multicolumn{3}{|l|}{ Grade group } & \multirow{2}{*}{$\begin{array}{l}\text { Grade group 1, } 2 \text { vs. 3, 4, } \\
5 \\
\text { AUC of ROC }\end{array}$} & \multirow[t]{2}{*}{ ICC } & \multirow[t]{2}{*}{$95 \% \mathrm{Cl}$} & \multicolumn{3}{|c|}{ Bland-Altman plot (\%) } \\
\hline & & $\begin{array}{l}\text { Spearman's } \\
\rho\end{array}$ & $95 \% \mathrm{Cl}$ & $p$ & & & & Bias & $\begin{array}{l}\text { SD of } \\
\text { bias }\end{array}$ & $95 \%$ LOA \\
\hline \multicolumn{11}{|c|}{$\operatorname{ADC}(100,1,500)$, bin 32} \\
\hline \multirow[t]{2}{*}{ SRHGE } & First & 0.488 & 0.02898 to 0.7771 & 0.034 & 0.814 & \multirow[t]{2}{*}{0.427} & \multirow[t]{2}{*}{-0.011 to 0.73} & \multirow[t]{2}{*}{-21.4} & \multirow[t]{2}{*}{27.77} & \multirow{2}{*}{$\begin{array}{l}-75.83 \text { to } \\
33.04\end{array}$} \\
\hline & Second & 0.6912 & 0.3326 to 0.8752 & 0.001 & 0.943 & & & & & \\
\hline \multirow[t]{2}{*}{ busyness } & First & -0.5039 & $\begin{array}{l}-0.7853 \text { to } \\
-0.05002\end{array}$ & 0.0278 & 0.814 & \multirow[t]{2}{*}{0.576} & \multirow[t]{2}{*}{$\begin{array}{l}0.188 \text { to } \\
0.811\end{array}$} & \multirow[t]{2}{*}{21.1} & \multirow[t]{2}{*}{77.36} & \multirow[t]{2}{*}{$\begin{array}{l}-130.5 \text { to } \\
172.7\end{array}$} \\
\hline & Second & -0.6742 & -0.8675 to -0.3039 & 0.0015 & 0.929 & & & & & \\
\hline \multicolumn{11}{|c|}{ DWI 100, bin 32} \\
\hline \multirow[t]{2}{*}{ skewness } & First & -0.5232 & $\begin{array}{l}-0.7951 \text { to } \\
-0.07612\end{array}$ & 0.0215 & 0.829 & \multirow[t]{2}{*}{0.629} & \multirow[t]{2}{*}{$\begin{array}{l}0.266 \text { to } \\
0.837\end{array}$} & \multirow[t]{2}{*}{-28.03} & \multirow[t]{2}{*}{310.3} & \multirow[t]{2}{*}{$\begin{array}{l}-636.2 \text { to } \\
580.1\end{array}$} \\
\hline & Second & -0.4699 & $\begin{array}{l}-0.7676 \text { to } \\
-0.005422\end{array}$ & 0.0424 & 0.786 & & & & & \\
\hline \multirow[t]{2}{*}{ HGRE } & First & 0.5663 & 0.1368 to 0.8166 & 0.0115 & 0.857 & 0.658 & 0.312 to & -14.68 & 35.99 & -85.22 to \\
\hline & Second & 0.5516 & 0.1157 to 0.8093 & 0.0144 & 0.843 & & & & & 55.8 \\
\hline SRHGE & First & 0.5663 & 0.1368 to 0.8166 & 0.0115 & 0.857 & 0.619 & 0.251 to & -15.33 & 35.93 & -85.76 to 55.1 \\
\hline & Second & 0.5902 & 0.1717 to 0.8282 & 0.0078 & 0.871 & & & & & \\
\hline LRHGE & First & 0.4892 & 0.03047 to 0.7777 & 0.0335 & 0.8 & 0.802 & 0.563 to & -12.04 & 37.52 & -85.58 to 61.5 \\
\hline & Second & 0.4744 & 0.01126 to 0.77 & 0.0401 & 0.786 & & & & & \\
\hline HGZE & First & 0.5277 & 0.08236 to 0.7974 & 0.0202 & 0.829 & 0.558 & 0.161 to & -13.03 & 32.89 & -77.5 to 51.44 \\
\hline & Second & 0.5277 & 0.08236 to 0.7974 & 0.0202 & 0.829 & & & & & \\
\hline SZHGE & First & 0.5516 & 0.1157 to 0.8093 & 0.0144 & 0.843 & 0.373 & -0.075 to & -14.48 & 33.09 & -79.34 to \\
\hline & Second & 0.6072 & 0.1974 to 0.8364 & 0.0058 & 0.886 & & & & & \\
\hline & First & -0.6151 & -0.8401 to -0.2095 & 0.0051 & 0.900 & 0.548 & 0.148 to & 9.866 & 44.39 & -77.14 to \\
\hline busyness & Second & -0.4642 & $\begin{array}{l}-0.7646 \text { to } \\
0.001836\end{array}$ & 0.0453 & 0.771 & & & & & \\
\hline DWI 0 , bin & 32 & & & & & & & & & \\
\hline & First & -0.5743 & -0.8205 to -0.1483 & 0.0101 & 0.871 & 0.575 & 0.185 to 0.81 & -55.02 & 303.2 & -649.3 to \\
\hline skewness & Second & -0.4982 & $\begin{array}{l}-0.7824 \text { to } \\
-0.04246\end{array}$ & 0.0299 & 0.800 & & & & & \\
\hline HGRE & First & 0.5947 & 0.1785 to 0.8304 & 0.0072 & 0.871 & 0.579 & 0.192 to & -14.98 & 34.32 & -82.24 to \\
\hline & Second & 0.4721 & 0.008339 to 0.7688 & 0.0412 & 0.786 & & 0.81 & & & 52.2 \\
\hline SRHGE & First & 0.614 & 0.2078 to 0.8396 & 0.0052 & 0.886 & 0.537 & 0.132 to & -15.22 & 34.93 & -83.67 to \\
\hline & Second & 0.4892 & 0.03047 to 0.7777 & 0.0335 & 0.8 & & & & & \\
\hline HGZE & First & 0.5947 & 0.1785 to 0.8304 & 0.0072 & 0.871 & 0.524 & 0.115 to & -10.79 & 32.12 & -73.75 to \\
\hline & Second & 0.4937 & 0.03645 to 0.78 & 0.0317 & 0.8 & & & & & \\
\hline
\end{tabular}

95\% Cl 95\% confidence interval, 95\% LOA 95\% Limit of agreement, AUC Area under the curve, HGRE High gray-level run emphasis, HGZE High gray-level zone emphasis, ICC Intraclass correlation coefficient, LRHGE Long-run high gray-level emphasis, ROC Receiver operating characteristic, SD Standard deviation, SRHGE Short-run high gray-level emphasis, SZHGE Short-zone high gray-level emphasis

observers, not carried out independently. We consider consensus reading would be acceptable because one of the main purposes of the present study was to assess reliability of the imaging data themselves. Finally, in both $\mathrm{PZ}$ and TZ cancer, the number of lesions was not sufficiently large; therefore, further analyses by combining features through logistic regression and/or discriminant analyses were not performed.
In conclusion, some DWI-related features showed significant correlation with GG and clinically acceptable data repeatability in histologically confirmed prostate cancer, and they differed between the PZ and TZ. The texture features for $\mathrm{TZ}$ cancer tended to show higher correlation with GG and higher discrimination ability between GG of 1 and 2 versus GG of 3, 4, and 5, but lower data repeatability than those for $\mathrm{PZ}$ cancer. 
Regarding a correlation with GG, DWI 100 and 1,500 s/ $\mathrm{mm}^{2}$, and ADC generated from these two images would be relevant.

\section{Abbreviations}

AUC: Area under the curve; GG: Grade group; GLCM: Gray-level cooccurrence matrix; GLZSM: Gray-level zone-size matrix; GS: Gleason score; HGRE: High gray-level run emphasis; HGZE: High gray-level zone emphasis; ICC: Intraclass correlation coefficient; LRE: Long-run emphasis; LRHGE: Longrun high gray-level emphasis; mpMRI: Multiparametric MRI; MRI: Magnetic resonance imaging; NGLDM: Neighborhood gray-level difference matrix; PIRADS: Prostate Imaging-Reporting and Data System; PZ: Peripheral zone; ROC: Receiver operating characteristic; ROI: Region of interest; SRE: Short-run emphasis; SRHGE: Short-run high gray-level emphasis; SZE: Short-zone emphasis; SZHGE: Short-zone high gray-level emphasis; TZ: Transition zone

\section{Supplementary Information}

The online version contains supplementary material available at https://doi. org/10.1186/s41747-021-00252-y.

Additional file 1: Supplemental Table 1 Acquisition parameters for diffusion-weighted imaging

\section{Authors' contributions}

All authors read, edited, and approved the final version of the manuscript. CT contributed to data acquisition, data analysis, and manuscript preparation. $\mathrm{KH}$ contributed to software creation, data analysis, interpretation, and manuscript editing. KK contributed to study concept, design, data interpretation, and manuscript editing. NM contributed to study design, MRI examination, data interpretation, and manuscript editing. $\mathrm{MH}$ contributed to study concept, design, data acquisition, data analysis, interpretation, and manuscript editing.

\section{Funding}

This work has not received any funding.

\section{Availability of data and materials}

The datasets used and/or analyzed during the current study are available from the corresponding author on reasonable request.

\section{Declarations}

\section{Ethics approval and consent to participate}

This prospective observational study was approved by the Sapporo University Hospital review board. All participants gave informed consent to this study.

\section{Consent for publication}

As part of the hospital treatment contract, informed written consent is obtained from all patients and/or their legal guardians for the use of their anonymized data for research purposes. No personal data is included in this manuscript.

\section{Competing interests}

The authors declare that they have no competing interests.

\section{Author details}

'Department of Diagnostic Radiology, School of Medicine, Sapporo Medical University, South 1, West 17, Chuo-ku, Sapporo 060-8556, Japan.

${ }^{2}$ Department of Diagnostic Imaging, Graduate School of Medicine, Hokkaido University, Sapporo, Japan. ${ }^{3}$ Global Center for Biomedical Science and Engineering, Faculty of Medicine, Hokkaido University, Sapporo, Japan. ${ }^{4}$ Department of Urology, School of Medicine, Sapporo Medical University, Sapporo, Japan.
Received: 29 June 2021 Accepted: 25 October 2021

Published online: 12 January 2022

\section{References}

1. Lubner MG, Smith AD, Sandrasegaran K, Sahani DV, Pickhardt PJ (2017) CT texture analysis: definitions, applications, biologic correlates, and challenges. Radiographics 37:1483-1503 https://pubs.rsna.org/doi/10.1148/rg.20171 70056

2. Schieda N, Lim CS, Zabihollahy F, et al (2021) Quantitative prostate MRI. J Magn Reson Imaging 53:1632-1645. https://doi.org/10.1002/jmri.27191

3. Lovinfosse P, Polus M, Van Daele D, et al (2018) FDG PET/CT radiomics for predicting the outcome of locally advanced rectal cancer. Eur J Nucl Med Mol Imaging 45:365-375. https://doi.org/10.1007/s00259-017-3855-5

4. Traverso A, Wee L, Dekker A, Gillies R (2018) Repeatability and Reproducibility of Radiomic Features: A Systematic Review. Int J Radiat Oncol Biol Phys 102:1143-1158. https://doi.org/10.1016/j.jijobp.2018.05.053

5. Varghese BA, Cen SY, Hwang DH, Duddalwar VA (2019) Texture Analysis of Imaging: What Radiologists Need to Know. AJR Am J Roentgenol 212: 520-528. https://www.ajronline.org/doi/10.2214/AJR.18.20624

6. Han S, Woo S, Suh CH, Kim YJ, Oh JS, Lee JJ (2018) A systematic review of the prognostic value of texture analysis in 18F-FDG PET in lung cancer. Ann Nucl Med 32:602-610. https://doi.org/10.1007/s12149-018-1281-9

7. Rosenkrantz AB, Triolo MJ, Melamed J, Rusinek H, Taneja SS, Deng FM (2015) Whole-lesion apparent diffusion coefficient metrics as a marker of percentage Gleason 4 component within gleason 7 prostate cancer at radical prostatectomy. J Magn Reson Imaging 41:708-714. https://doi.org/1 0.1002/jmri.24598

8. Alessandrino F, Taghipour M, Hassanzadeh E, et al (2019) Predictive role of PI-RADSV2 and ADC parameters indifferentiating Gleason pattern $3+4$ and $4+3$ prostate cancer. Abdom Radiol (NY) 44:279-285. https://doi.org/10.1 007/s00261-018-1718-6.

9. Itou Y, Nakanishi K, Narumi Y, Nishizawa Y, Tsukuma H (2011) Clinical utility of apparent diffusion coefficient (ADC) values in patients with prostate cancer: Can ADC values contribute to assess the aggressiveness of prostate cancer? J Magn Reson Imaging 33:167-172. https://doi.org/10.1002/ jmri.22317

10. Shan Y, Chen X, Liu K, et al (2019) Prostate cancer aggressive prediction: preponderant diagnostic performances of intravoxel incoherent motion (IVIM) imaging and diffusion kurtosis imaging (DKI) beyond ADC at 3.0 T scanner with gleason score at final pathology. Abdom Radiol 44: 3441-3452. https://doi.org/10.1007/s00261-019-02075-3

11. Diaz de Leon A, Leyendecker JR, Otero-Muinelo S et al (2018) Reproducibility of Index Lesion Size and Mean Apparent Diffusion Coefficient Values Measured by Prostate Multiparametric MRI: Correlation With Whole-Mount Sectioning of Specimens. AJR Am J Roentgenol 211: 783-788. https://www.ajronline.org/doi/10.2214/AJR.17.19172

12. Nguyen TB, Ushinsky A, Yang A et al (2018) Utility of quantitative apparent diffusion coefficient measurements and normalized apparent diffusion coefficient ratios in the diagnosis of clinically significant peripheral zone prostate cancer. Br J Radiol 91:20180091. https://www.birpublications.org/ doi/10.1259/bjr.20180091

13. Hambrock T, Somford DM, Huisman HJ, et al (2011) Relationship between apparent diffusion coefficients at 3. 0-T MR imaging and Gleason Grade in peripheral zone prostate cancer. Radiology 259:453-461. https://pubs.rsna. org/doi/10.1148/radiol.11091409

14. Jyoti R, Jain TP, Haxhimolla H, Liddell H, Barrett SE (2018) Correlation of apparent diffusion coefficient ratio on 3.0 T MRI with prostate cancer Gleason score. Eur J Radiol Open 5:58—63. https://doi.org/10.1016/j.ejro.201 8.03 .002

15. Surov A, Meyer HJ, Wienke A (2020) Correlations between Apparent Diffusion Coefficient and Gleason Score in Prostate Cancer: A Systematic Review. Eur Urol Oncol 3:489—497. https://doi.org/10.1016/j.euo.2018.12.006

16. Manabe O, Ohira $\mathrm{H}$, Hirata $\mathrm{K}$, et al (2019) Use of 18 F-FDG PET/CT texture analysis to diagnose cardiac sarcoidosis. Eur J Nucl Med Mol Imaging 46: 1240-1247. https://doi.org/10.1007/s00259-018-4195-9

17. Stark JR, Perner S, Stampfer MJ, et al (2009) Gleason score and lethal prostate cancer: Does $3+4=4+3$ ? J Clin Oncol 27:3459-3464. https:// doi.org/10.1200/JCO.2008.20.4669

18. Hosmer DW Jr. Lemeshow S, Sturdivant RX (eds) (2013) Applied Logistic Regression, 3rd Edition. Wiley, New York 
19. Koo TK, Li MY (2016) A Guideline of Selecting and Reporting Intraclass Correlation Coefficients for Reliability Research. J Chiropr Med 15:155-163. https://doi.org/10.1016/j.jcm.2016.02.012

20. Hectors SJ, Cherny M, Yadav KK, et al (2019) Radiomics features measured with multiparametric magnetic resonance imaging predict prostate cancer aggressiveness. J Urol 202:498—504. https://doi.org/10.1097/JU. 0000000000000272

21. Baek TW, Kim SH, Park SJ, Park EJ (2020) Texture analysis on bi-parametric MRI for evaluation of aggressiveness in patients with prostate cancer. Abdom Radiol (NY) 45:4214-4222. https://doi.org/10.1007/s00261-020-02 683-4

22. Kwak JT, Sankineni S, Xu S, et al (2017) Prostate cancer: A correlative study of Multiparametric MR imaging and digital histopathology. Radiology 285: 147-156. https://doi.org/10.1148/radiol.2017160906

23. Chatterjee A, Bourne RM, Wang S, et al (2018) Diagnosis of prostate cancer with noninvasive estimation of prostate tissue composition by using hybrid multidimensional MR imaging: A feasibility study. Radiology 287:863-873. https://doi.org/10.1148/radiol.2018171130

24. Liu Y, Wang X, Cui Y, et al (2020) Comparative Study of Monoexponential, Intravoxel Incoherent Motion, Kurtosis, and IVIM-Kurtosis Models for the Diagnosis and Aggressiveness Assessment of Prostate Cancer. Front Oncol 10:1763. https://doi.org/10.3389/fonc.2020.01763

25. Niu X, Chen Z, Li L et al (2018) Clinical Application of Biparametric MRI Texture Analysis for Detection and Evaluation of High-Grade Prostate Cancer in Zone-Specific Regions. AJR Am J Roentgenol 210:549-556 https:// www.ajronline.org/doi/10.2214/AJR.17.18494.

26. Smith CP, Harmon SA, Barrett T, et al (2019) Intra- and interreader reproducibility of PI-RADSv2: A multireader study. J Magn Reson Imaging 49:1694-1703. https://doi.org/10.1002/jmri.26555.

\section{Publisher's Note}

Springer Nature remains neutral with regard to jurisdictional claims in published maps and institutional affiliations.

\section{Submit your manuscript to a SpringerOpen ${ }^{\circ}$ journal and benefit from:}

- Convenient online submission

- Rigorous peer review

- Open access: articles freely available online

- High visibility within the field

- Retaining the copyright to your article

Submit your next manuscript at $\boldsymbol{\nabla}$ springeropen.com 